\title{
Türkiye Pay Endeks Futures Piyasasında Optimum Korunma Oranı ve Korunma Etkililiği
}

\author{
Optimal Hedge Ratio and Hedging Effectiveness in Turkish Stock Index \\ Futures Market
}

İbrahim Yaşar GÖK ${ }^{1}$

\begin{abstract}
ÖZET
Bu çalışmada Türkiye endeks futures piyasasında optimal korunma oranı ve korunma performansı araştırılmış, günlük korunma ile bir, iki, üç ve dört haftalık korunma olmak üzere beş farklı korunma zamanı incelenmiştir. Çalışmada, en küçük kareler (OLS), hata düzeltme modeli (ECM), genelleştirilmiş otoregresif koşullu değişen varyans (GARCH) modeli, ECM-GARCH modeli ve çok değişkenli GARCH modellerinden diyagonal VECH-GARCH ve diyagonal BEKK-GARCH modelleri olmak üzere altı farklı model uygulanmış ve 1 Kasım 2005 ve 30 Ekim 2015 arası dönemde BIST 30 endeksi spot ve futures piyasalarına ait gün sonu veriler kullanılmıştır. Günlük korunmada en iyi korunma oranını ECMGARCH modeli sağlarken, diğer korunma zamanları için çok değişkenli GARCH modelleri en iyi korunma oranlarını sağlamaktadır. Risk-getiri korunma performansı açısından ise her ne kadar iki ve dört haftalık korunma zamanlarında en iyi performansa klasik OLS modeli sahip olsa da, diğer korunma zamanlarında en iyi model farklılaşmaktadır. Ayrıca, korunma zamanı uzadıkça korunma performansı da artmaktadır. Bu bulgular perspektifinde, modellerin performansları birbirine yakın olup, tüm korunma zamanları için tek bir en iyi modele erişilemese de, BIST 30 endeks futures kontratların etkin korunma araçları olduğuna ulaşılmıştır. Risk-getiri dengelemesi açısından, tercih edilen korunma zamanı için uygun olan modelle, yatırımcılar en iyi performansı elde edebileceklerdir.
\end{abstract}

Anahtar Kelimeler: Korunma Oranı, Korunma Etkililiği, Korunma Zamanı, Futures Kontrat

\begin{abstract}
In this study, optimum hedge ratio and hedging effectiveness of Turkish index futures market are investigated and five different hedging horizons including daily hedging and one, two, three, and four weeks hedging are examined. In the study, six different models including ordinary least squares $(\mathrm{OLS})$, error correction model (ECM), generalized autoregressive conditional heteroskedasticity (GARCH) model, ECM-GARCH model and from multivariate GARCH models diag VECH-GARCH and diag BEKK-GARCH models are applied and daily spot and futures data of BIST 30 index in the period of November 1, 1995 and October 30, 2014 is used. While the best hedge ratio for daily hedging is provided by ECM-GARCH model, for the other hedge horizons the best hedge ratios are provided by multivarite GARCH models. In the view of riskreturn hedging performance, although OLS model has the best performance in two and four week hedging horizons, for the other hedging horizons the best model differentiates. Also, hedging performance increases with extending the hedging horizon. In the perspective of these findings, it is concluded that though the performances of the models are close to each other and it is not reached one best model, BIST 30 index contracts are effective hedging instruments. In the view of riskreturn trade off, investors can benefit with the best performance by the proper model for the preferred hedging horizon.
\end{abstract}

Key Words: Hedge Ratio, Hedging Effectiveness, Hedge Horizon, Futures Contract 


\section{GíRiş}

Futures kontratların en önemli kullanım alanlarından birisi riskten korunmayı (hedging) sağlayabilmeleridir. Spot piyasa işlemlerinde bir fiyat riski ile karşılaşılır. Örneğin, Borsa İstanbul (BIST) 30 endeksinin bileşenlerinden oluşan bir portföyün değerizaman içerisindeazalabilir.Spot piyasadaalınan bu pozisyon karşısında, spot piyasanın tersi bir futures pozisyon alarak riskten korunma sağlanabilir. Spot piyasada alım (long) yapıldığında, zaman içerisinde spot piyasadaki fiyatların azalması söz konusu olursa, alınan tersi futures satış (short) pozisyonu ile kazanç elde edilecek, bu sayede bir piyasadaki kayıp (kazanç) ile diğer bir piyasadaki kazanç (kayıp) birbirini dengeleyecektir. İşte özellikle, 1970'lardan itibaren ortaya çıkan finansal futures piyasalar ile finansal varlıkların fiyat riskine karşı korunma fırsatı da ortaya çıkmıştır. Araştırmacılar ise bu korunma fırsatının nasıl uygulanabileceğine odaklanmış ve korunma oranının nasıl hesaplanabileceği ile korunma etkililiğinin (hedging effectiveness) nasıl ölçüleceği sorularına yanıt aramışlardır.

Optimal korunma oranı (optimal hedge ratio, OHR), en temel tanımıyla spot piyasadaki pozisyonun ne kadarı büyüklükte bir tersine futures pozisyon alınacağının belirlenmeye çalışılmasıdır. $X$ birim uzun spot pozisyona karşılık $Y$ birim kısa futures pozisyon alınması durumunda, " $h$ " korunma oranı olmak üzere $h=Y / X$ şeklinde hesaplanır. Örneğin, spot piyasada BIST 30 endeksi bileşenlerinin, endeksteki yer alma yüzdeleri ile aynı şekilde oluşturulan bir portföyün bugünkü değerinin 1.5 milyon TL olduğu varsayımı ile, bu 1.5 milyon TL'nin ne kadarını kapsayacak (cover) şekilde BIST 30 endeks futures kontratı satılacağının araştırılması, portföyün korunma oranının hesaplanmaya çalışılmasıdır.

OHR'nin hesaplanmasına dönük olarak, Johnson (1960) minumum varyans korunma oranını (minimum variance hedge ratio, MVHR) önermiștir. MVHR, hesaplaması basit ve en yaygın kullanılan korunma oranlarından birisi olagelmiştir. Klasik korunmanın tam olarak korunma ve Working'in' korunma teorisinin tam korunma ya da hiç korunmama önerileri bir yana, portföy teorisini uygulamakla birlikte Johnson (1960) ve Stein (1961) hem korunulan hem de korunulmayan pozisyonların bir arada olmasını gerektiren bir konsepti önermişlerdir (Ederington, 1979). MVHR, korunulan portföyün varyansının minimize edilmesi yaklaşımına dayanır. Bu yaklaşıma göre, spot ve futures getirilerin kovaryansının, futures getirinin varyansına bölünmesi ile MVHR elde edilir. Buna göre, $R_{s}$ ve $R_{f}$ sirasiyla spot ve futures getiriler ve " $h$ " MVHR'yi belirtmek üzere, MVHR,

$h=\operatorname{Cov}\left(R_{s}, R_{f}\right) / R_{f}$

ile hesaplanır. Ederington (1979), MVHR'nin elde edilebilmesi için spot getiriler ile futures getiriler arasında bir en küçük kareler (OLS) tahmini yapılarak, futures getiri katsayısını MVHR olarak baz almayı öne sürmüştür. Buna göre,

$R_{s}=a+b \Delta R_{f}+e_{t}$

şeklinde tahmin edilen OLS denkleminde " $b$ " parametresi MVHR'ye karşılık gelmektedir. Ancak OLS yaklaşımına da çeşitli eleştiriler getirilmiştir. Özellikle de getiri dağılımlarının - pek çok kere görüldüğü üzere- zaman içerisinde değişiyor olmasından ötürü korunma oranının aslında zaman içerisinde değişim gösteriyor olması ancak OLS tahmininde bu durumun ihmal edilmesi, OLS tahmininin -pek çok kere görüldüğü üzere- hatanın değişen varyans ve otokorelasyon sahip olmaması varsayımını inmal edilerek gerçekleştirilmesi ve OLS yönteminin spot ve futures fiyatlar arasındaki uzun dönem ilişkileri analiz etmeye imkan vermemesi gibi eleştiriler yöneltilmektedir. Bu bağlamda, araştırmacıların hata düzeltme modeli (ECM), vektör hata düzeltme modeli (VECM), tek ve çok değişkenli genelleştirilmiş otoregresif koşullu değişen varyans (GARCH) modelleri, ECM-GARCH modeli vb. yöntemleri de kullandıkları dikkati çekmekte, çoğu kere de birden çok yöntem bir arada kullanılarak bu yöntemlerle elde edilen korunma oranları karşılaştırılmakta ve korunma etkililiğinin nasıl farklılaştığı araştııılmaktadır.

$\mathrm{Bu}$ çalışmada, BIST 30 endeksine dayalı bir portföyün BIST 30 endeks futures kontratlar kullanılarak optimal korunma oranının, 1 gün, 1 hafta, 2 hafta, 3 hafta ve 4 haftalık korunma zamanları (hedging horizon) bağlamında hesaplanması amaçlanmıştır. Ayrıca, futures kontratların vadeye kalan zamanının OHR üzerindeki etkisinin de araştırılması amaçlanmıştır. OHR'nin hesaplanması için OLS, ECM, GARCH, ECM-GARCH modelleri ile çok değişkenli GARCH modellerinden (M-GARCH) diyagonal VECH ve diyagonal BEKK

'Ederington (1979), alım pozisyonu sahibi için, Working (1953)'in korunma teorisini ya hep ya hiç şeklinde açıklamış, her zaman geçerli olmamakla birlikte, eğer baz azalıyorsa klasik korunmanın yapılması, baz artıyorsa da korunma yapılmaması șeklinde özetlemiştir. 720 
modelleri uygulanarak karşılaştırmalı bir analiz gerçekleştirilmiştir. Bu sayede hem statik hem de dinamik korunma oranları bir arada ele alınmıştır. Çalışmada, farklı korunma zamanları çerçevesinde OHR'nin elde edilmesi ve futures kontratların vadeye kalan zamanının OHR üzerine etkisi Türkiye piyasaları üzerinde ilk kez araştırılmıştır.

Çalışma, ikinci bölümde literatür araştırması ile devam etmekte, üçüncü bölümde ise araştırma dizaynı kapsamında veri setinin tanıtılması, metodoloji ve araştırma bulguları yer almakta ve sonuç bölümüyle de çalışma sonlanmaktadır.

\section{LITERATÜR ARAŞTIRMASI}

Figlewski (1985) endeks futures kontratların 1982'de ilk olarak tanıtılmasının ardından ABD'de endeks futures kontratlarla korunma üzerine öncül bir çalışma gerçekleştirmiştir. Daha endeks futures piyasaların başlangıç aşamasında sınırlı bir veri ile yaptığı çalışmasında, daha uzun korunma zamanları ile MVHR'nin artma eğiliminde olduğu, daha çok sayıda payı içeren portföylerle korunmanın daha etkin olduğu bulgularına erişmiş, her ne kadar sabit korunma oranıyla çalışmasını sınırlasa da futures kontrat vadeye yaklaştıkça baz riski azalırsa zamanla korunma oranının artacağı, bundan ötürü de dinamik bir korunma stratejisinin uygulanabileceğini ifade etmiştir. Lindahl (1992) çalışmasında yine ABD piyasalarına dönük, Major Piyasa Endeksi (MMI) ve Standart and Poors (S\&P) 500 endeks futures kontratlarla korunmayı araştırmış, OLS, sınırlandırılmış en küçük kareler ve çoklu OLS modellerini uygulamış ve MMI için 1985-1989 dönemi ile S\&P 500 için 1983-1989 dönemini, bir, iki ve dört haftalık korunma zamanları çerçevesinde incelemiştir. Her iki piyasa için de korunma zamanı arttıkça MVHR'nin anlamlı bir şekilde arttığı, ancak futures kontrat vadeye yaklaştıkça bu etkinin kalktığı, ayrıca futures kontrat vadeye yaklaştıkça MVHR'nin artış gösterdiği bulgularına erişmiştir. In ve Kim (2006) ise S\&P 500 endeksi spot ve futures piyasaları üzerine yaptıkları çalışmada, Nisan 1982 ve Aralık 2001 arası gün sonu verileri kullanmış ve küçük dalga analizini uygulamışlardır. Buna göre, zaman ölçeğine bağlı kalmaksızın spot ve futures piyasaların bir geri besleme ilişkisi sergilediği ve taşıma maliyeti hipotezinin varsayımları çerçevesinde iki piyasanın da mükemmel etkin oldukları, ayrıca iki piyasa arasındaki küçük dalga korelasyon oranlarının zaman içerisinde değişim sergilemekle beraber oldukça yüksek olduğu ve zaman ölçeği arttıkça korelasyon büyüklüğünün de arttığı, bununla beraber dönemler arası korunma oranı incelendiğinde ise her korunma zamanının kendisine ait bir korunma oranı olduğu ve uzun dönem korunma oranının 1'e yakınsadığı bulgularına erişmişlerdir.

Birleşik Krallık piyasalarına dönük olarak, Holmes (1995) FTSE 100 endeks futures kontratların korunma etkililiğini araştırdığı çalışmasında, kendisinden önceki çalışmalarda kullanılan ex-post korunma oranları yerine ex-ante korunma oranlarını kullanmış, 1984-1992 arası dönemde MVHR'yi OLS yöntemiyle araştırmıştır. Ex-post korunma oranları yıllık bazda hesaplanıp takip eden yıl için kullanılırken, exante korunma oranlarını ise dinamik bir şekilde ilk $j$ periyot için hesaplandıktan sonra takip eden dönemde kullanılması, sonrasında da ilk gözlemin çıkarılıp j+1'inci gözlemin eklenmesiyle her $j$ periyodu için korunma oranlarının hesaplanması şeklinde açıklamıştır. Çalışmasında, korunma oranları zamana bağlı olarak değişse de FTSE-100 endeks futures kontratların haftalık korunmada yaklaşık \%80 ve iki haftalık korunmada yaklaşık \%85'e kadar risk azalmasını başardığına ulaşmış, öte taraftan ex-post korunma oranlarının korunma etkililiğinin daha yüksek tahmin edilmesine yol açtığı bulgularına erişmiştir.

Avustralya piyasalarına dönük olarak, Yang ve Allen (2004) Avustralya Bileşik Pay Endeksi (AOI) ve buna dayalı futures kontratların kullanılmasıyla OHR'yi tahmin etmek için OLS, vektör otoregresyon (VAR), VECM ve çok değişkenli diyagonal VECGARCH modellerini uygulamış ve Haziran 1992 ve Aralık 2000 arası gün sonu verileri kullanmışlardır. Korunma etkililiğini risk-getiri karşılaştırması ve fayda maksimizasyonu metodlarını kullanarak ölçtükleri çalışmalarında, zamana bağlı değişen GARCH korunma oranlarının sabit korunma oranları yerine risk minimizasyonunda daha iyi performans sergilediği, ancak getiri etkisi de dikkate alındığında fayda bazlı metodun örneklem içi korunmada OLS modelini öne çıkardığı, diğer taraftan örneklem dışı korunmada ise her iki metodun da çok değişkenli GARCH korunma oranını öne çıkardıkları bulgularına erişmişlerdir.

Yunanistan piyasalarına dönük olarak, Floros ve Vougas (2004) FTSE/ASE-20 ve FTSE/Mid 40 endeks futures piyasaları ile korunmayı araştırdıkları çalışmalarında, FTSE/ASE-20 spot ve futures piyasaları 
için 525 günlük veri, FTSE/Mid 40 piyasaları için 415 günlük veri kullanmış, OLS, ECM, VECM ve M-GARCH modellerini uygulamışlardır. Her iki endeks futures piyasa için de, M-GARCH modellerinin en iyi korunma oranlarını verdiği bulgularına erişmiş ve bu modelleri güçlü bir şekilde tavsiye etmişlerdir. Kavussanos ve Visvikis (2008) yine Yunanistan endeks futures piyasaları üzerine yaptıkları çalışmada, Eylül 1999 ve Haziran 2004 arası günlük ve haftalık verileri kullanmış ve OLS, VECM ve VECM-GARCH modellerini uygulamışlardır. Çalışmalarında, örneklem içi testlerde zamana bağlı değişen korunma oranlarının diğer spesifikasyonlardan daha iyi performans sağladığı, örneklem dışı testlerde ise daha basit modellerden elde edilen sabit korunma oranının maksimum varyans azalışı ve fayda artışını sağladığı bulgularına erişmişlerdir.

Güney Afrika piyasalarına yönelik, Degiannakis ve Floros (2010) Ocak 2002 ve Şubat 2006 arası dönemde gün sonu verileri kullanmış ve OLS, ECM, VECM, ECM$\mathrm{GARCH}$, sabit koşullu korelasyon GARCH ve GARCHBEKK modellerini uygulamışlardır. Çalışmalarında, ECM-GARCH korunma oranının diğer modellerden elde edilen korunma oranlarından daha yüksek olduğu ve ECM-GARCH ile tahmin edilen korunma oranının korunmayı anlamlı şekilde geliştirdiği bulgusuna erişmişlerdir.

Türkiye piyasalarına yönelik, Olgun ve Yetkiner (2011), BIST 30 endeks futures piyasa için OHR'nin belirlenmesine dönük çalışmalarında, OLS ve iki değişkenli VECH-GARCH modellerini uygulamış ve Mayıs 2005 ile Eylül 2009 arası verileri kullanmışlardır. Çalışmalarında, iki değişkenli GARCH modeli ile dinamik bir korunmanın, OLS ile statik korunmaya göre daha üst düzey bir fayda maksimizasyonu sağladığına erişmişlerdir. Çelik (2014) ise BIST 30 endeks futures piyasa için OHR'yi, statik (geleneksel OLS, ECM, VECM ve ECM-GARCH) ve dinamik (VEC-CCC-GARCH ve VEC-Diag-BEKK) yöntemleri kullanarak tahmin etmiş, dinamik yöntemlerle yapılan tahminlerin statik yöntemlerden daha güvenilir ve tutarlı olduğunu elde etmiş, ayrıca dinamik yöntemler arasında CCC-GARCH modeli ile statik yöntemler arasında ECM-GARCH modelinin diğer modellere üstünlük sağladığına ulaşmıştır.

Bazı çalışmalarda ise birden fazla ülke piyasası bir arada araştırılmıştır. Sultan ve Hasan (2008) FTSE 100, Fransa'dan CAC 40, Almanya'dan DAX 30 ve Hollanda'dan Amsterdam Borsa Endeksi (AEX) futures piyasalarında dinamik korunmanın etkinliğini araştırdıkları çalışmalarında, Birleşik Kralıı, Hollanda ve Almanya için 1990-2006 arası ve Fransa için 19992006 arasıgünlükvehaftalıkverilerikullanmış, OHR'nin tahmini için iki değişkenli ECM-GARCH, iki değişkenli GARCH-X ve OLS modellerini uygulamışlardır. Buna göre, iki değişkenli ECM-GARCH modelinin dört piyasadan üçü için OHR'nin sabit olarak tahmin edildiği modellere göre daha yüksek risk azaltımını sağladığı, iki değişkenli GARCH-X modelinin de ECMGARCH modeline benzer bir performans sergilediği bulgularına erişmişlerdir.

Lee, Wang ve Chen (2009) ABD'den S\&P 500 ve Asya piyasalarına yönelik olarak Japonya'dan Nikkei 225, Kore Bileşik Pay Fiyat Endeksi (KOSPI) 200, Tayvan Kapitilizasyon Ağırlıkı Pay Endeksi (TAIEX), Hong Kong'tan Hang Seng endeksi ve Singapur'dan Strait Times endeksi futures kontratlarının optimal korunma oranlarını araştırdıkları çalışmalarında, Ocak 1997 ve Haziran 2003 arası dönemi araştırmış, OHR'nin elde edilmesi için MVHR'yi OLS ve iki değişkenli GARCH modeli ile hesaplarlarken, ayrıca ortalamavaryans korunma oranı, sharpe korunma oranı ve MEG korunma oranlarıyla da OHR'yi hesaplamışlardır. Çalışmalarında, minimum varyans GARCH korunma oranının OLS korunma oranından daha etkin olduğu, farklı piyasalarda OHR için kullanılan metodların bir ayırıcılığına ulaşılamadığı, ancak tüm endeks futures piyasaların korunma zamanı fark etmeksizin etkin korunma araçları olduğu bulgusuna erişmişlerdir.

Salvador ve Aragó (2014) FTSE-100, DAX 30 ve Avrupa geneline ait Eurostoxx 50 endeks futures piyaların korunma etkililiğini ölçtükleriçalışmalarında, Haziran 1998 ve Eylül 2010 arası verileri kullanmış, doğrusal ve doğrusal olmayan iki değişkenli GARCH modellerini uygulamışlardır. Çalışmalarında, rejimdeğişim modeliyle doğrusal olmayan yaklaşım ele alınmış ve doğrusal olmayan modelle diğer modellere göre daha etkin korunma oranları ve korunma performanslarının elde edildiğine ulaşmışlardır.

Hsu ve Chen (2014) sayısal zeka ve istatistik metodolojilerinin kombine edildiği çalışmalarında MVHR'nin doğru olarak tahmin edilmesini geliştirici farklı bir yaklaşım öne sürmüş, bu yaklaşımda piyasa dalgalanmalarının dinamik davranışlarına dayanan getirilerin hiyerarşik olarak kümelenmesini önermişlerdir. S\&P 500, FTSE 100, Nikkei 225 ve TAIEX pay endeksi spot ve futures piyasaları üzerine uygulamalarında, önerilen modelin orta ve uzun 
zamanlı korunmada OHR kararlarını OLS modeli ve birebir korunmaya göre anlamlı şekilde iyileştirdiği bulgularına erişmişlerdir.

Lien, Shrestha ve Wu (2015) aralarında S\&P 500, TOPIX, Nikkei 225, FTSE 100, CAC 40 ve AOI endeks futures kontratlarının da yer aldığı yirmi futures piyasa için OHR'yi yüzde (quantile) tahminiyle 15 yüzde de tahmin etmişlerdir. Geleneksel korunma oranının spot ve futures getirilerden türetildiğini, ancak gerçekleşen spot getiri, dağılımın uç yüzdelerine düştüğünde bunun uygun olmayabileceğini ifade etmiş ve geleneksel korunma oranının uygunluğunun analizi için yüzde korunma oranı yaklaşımını önermişlerdir. Günlük veriler için yüzde korunma oranının spot getiri dağılımına bağlı olduğu ve spot dağılımın aşağı ve yukarı kuyruklarında genellikle daha küçük olduğu, ancak bunun daha çok tarımsal futures kontratlar için geçerli olduğu, endeks futures kontratlar gibi diğer kontratlar için daha az geçerli olduğu bulgularına erişmişlerdir.

\section{ARAŞTIRMA DIZAYNI}

\subsection{Veri Seti}

Çalışmada BIST 30 endeksi ve BIST 30 endeks futures kontratlarına ait 01.11.2005 ve 30.10.2014 arası dönemde gün sonu veriler kullanılmıştır. Bu amaçla BIST 30 endeksi spot piyasa verileri için 2 . seans kapanış verileri ve BIST 30 endeksi futures piyasa verileri için de gün sonu uzlaşma fiyatları baz alınmıştır². Spot ve futures fiyat serilerinin logaritmik dönüşümleri gerçekleştirilmiş ve logaritmik fiyatların farkı alınarak getiri serileri hesaplanmıştır. Çalışma farklı korunma zamanları perspektifinde ele alınmış, günlük, haftalık, 2 haftalık, 3 haftalık ve 4 haftalık korunma zamanları için korunma oranları ve korunma performansları hesaplanmıştır. Bu doğrultuda, haftalık korunma zamanı cumadan cumaya fiyat serileri, iki, üç ve dört haftalık korunma zamanları ise sırasıyla iki haftada bir, üç haftada bir ve dört haftada bir cumadan cumaya fiyat serilerinin baz alınmasıyla hesaplanmıştır. Çalışmada, 2259 günlük veri, 465 haftalık veri, 234 iki haftalık veri, 157 üç haftalık veri ve 117 dört haftalık veri kullanılmıştır. Çalışmada futures kontrat fiyat serisi oluşturmak amacıyla en yakın vadeli futures kontrat kullanılmış, en yakın vadeli kontratın vade tarihinden sonra diğer en yakın vadeli kontrata geçilerek kontratlar birbirine bağlanmıştır.
Çalışmada kullanılan spot ve futures piyasa verileri Borsa İstanbul'dan temin edilmiştir.

\subsection{Metodoloji}

Çalışmada, OHR'nin elde edilmesi amacıyla MVHR'nin hesaplanması OLS, ECM, GARCH, ECM-GARCH modelleri ile çok değişkenli GARCH modellerinden diyagonal $\mathrm{VECH}$ ve diyagonal BEKK modellerinin uygulanmasıyla gerçekleştirilmiştir. Bunlardan OLS korunma oranı statik korunma oranı olarak tanımlanırken, zamana bağlı değişen çok değişkenli GARCH korunma oranları ise dinamik korunma olarak tanımlanmaktadır. Lien, Shrestha ve Wu (2015) OHR'nin OLS ile tahminine dair eleştirilerden birinin OLS tahmininin seriler arasındaki eşbütünleşmeyi dikkate almaması ve eğer seriler arasında eşbütünleşme varsa hata düzeltme terimi OLS denklemine dahil edilmeden yapılacak bir tahminin eksik belirlemeye neden olacağını ifade etmişlerdir. İlk olarak Engle ve Granger (1987) tarafından önerilen hata düzeltme modeli, eğer iki fiyat serisi de I(1) ise bu seriler arasındaki regresyon denkleminden elde edilecek hata terimi serisine birim kök testi uygulamayı ve seri birim kök içermiyorsa bu iki serinin eşbütünleşik olduğu anlamına geldiği ve bu taktirde getiri serileri arasındaki tahmin edilecek OLS denklemine ilk tahmindeki hata terimlerinin dahil edilmesiyle hata düzeltme modelinin tahmin edilebileceği şeklindedir.

Holmes (1996) ile Lien ve Shrestha (2005) takip edilerek öncelikle denklem 3.'teki logaritmik fiyat serileri arasındaki OLS denklemi tahmin edilmiş ve hata terimlerine birim kök testi uygulanmış, sonrasında da denklem 4.'teki hata düzeltme modeli tahmin edilmiştir ${ }^{3}$. Burada, denklem 3.'te ve sırasıyla $t$ anındaki logaritmik spot ve logaritmik futures fiyatları ifade etmekte olup, $\Delta S=S_{t}-S_{t-1}$ ve $\Delta F=F_{t}-F_{t-1}$ 'dir. Denklem 4.'te ise " $u_{t-1}$ ", denklem 3.'ten elde edilen hata terimlerini ve $\beta_{1}$ ise optimal korunma oranını ifade etmektedir.

$$
\begin{aligned}
& S_{t}=a_{1}+a_{2} F_{t}+u_{t} \\
& \Delta S_{t}=\beta_{1} \Delta F_{t}+\beta_{2}+\beta_{3} u_{t-1}+\varepsilon_{t}
\end{aligned}
$$

OHR'nin OLS ile tahminine dair bir diğer eleştiri ise OLS tahmininden elde edilen hata terimlerinin varyansının sabit olduğu varsayımıdır, ancak pek çok zaman serisinde hatanın varyansının sabit olmadığına ulaşılmaktadır. İlk olarak Engle (1982) tarafından 
önerilen hatanın koşullu varyansının hatanın gecikmeli değerlerinin karesi ile modellenmesine ilişkin otoregresif koşullu varyans modeli (ARCH), koşullu değişen varyansın modellenmesine izin vermektedir. Sonrasında Bollerslev (1986) tarafından önerilen GARCH modeli ise ARCH modelinin genelleştirilmiş halidir ve hataların koşullu varyansının hem hatanın gecikmeli değerlerinin karesi hem

$$
\begin{aligned}
& \Delta S_{t}=a+b \Delta F_{t}+u_{t} \quad u_{t} \sim N\left(0, \sigma_{t}^{2}\right) \\
& \sigma_{t}^{2}=\alpha_{0}+\alpha_{1} u_{t-1}^{2}+\beta \sigma_{t-1}^{2}
\end{aligned}
$$

Diğer taraftan, denklem 5.te yer alan ortalama denklemi yerine denklem 4.te yer alan ECM denklemi kullanılarak, ECM-GARCH modeli de kurgulananilir. $\mathrm{Bu}$ bağlamda çalışmada ECM-GARCH modeli de kullanılmıştır. Pek çok çalışmada ${ }^{4}$ ise çok değişkenli GARCH modellerinin de kullanıldığı görülmektedir. $\mathrm{Bu}$ çalışmada, çok değişkenli GARCH modelleri arasından, Bollerslev vd. (1988) tarafından önerilen de koşullu varyansın kendi gecikmeli değerleri ile modellenmesini öngörmektedir. En bilinen GARCH modeli ise GARCH $(1,1)$ modelidir. Holmes (1996)'u takip ederek, OHR'nin GARCH $(1,1)$ modeli ile elde edilmesi ise sırasıyla denklem 5. ve 6.'da ki ortalama ve varyans denklemlerinin tahmin edilmesi ile hesaplanmıştır. Burada, ortalama denklemindeki " $b$ " OHR'yi vermektedir.

diyagonal VECH modeli ile Engle ve Kroner (1995) tarafından önerilen BEKK modeli kullanılmıştır. Salvador ve Aragó (2014) iki değişkenli BEKK modelini kullandıkları çalışmalarında, fiyat serileri arasında eşbütünleşme ilişkisi de bulunduğu için ortalama denklemine hata düzeltme terimini de ilave etmişlerdir. Çalışmalarında, ortalama denklemine dair aşağıdaki spesifikasyonu tanımlamışlardır ki,

$$
\begin{aligned}
& \Delta S_{t}=a_{0}+a_{1} \Delta S_{t-1}+a_{2} \Delta F_{t-1}+a_{3} E C T_{t-1}+e_{s, t} \\
& \Delta F_{t}=b_{0}+b_{1} \Delta F_{t-1}+b_{2} \Delta S_{t-1}+b_{3} E C T_{t-1}+e_{f, t} \\
& e_{t}\left|\grave{\mathrm{U}}_{t-1}=\left(\frac{e_{s, t}}{e_{f, t}}\right)\right| \grave{\mathrm{U}}_{t-1} \sim B N\left(0, H_{t}\right)
\end{aligned}
$$

burada, ECT, hata düzeltme terimleri ve $i=\{0,1,2,3\}$ için $a_{i}$ ile $b_{i}$ tahmin edilecek parametreler, $e_{s, t}$ ve $e_{f, t}$ sırasiyla spot ve futures inovasyonlar, $\grave{U}_{t-1}$ ise $t-1$ ' e kadar erişilebilir bilgi seti, $B N$ iki değişkenli normal dağılım ve $H_{t}$ ise pozitif tanımlı zamana bağlı değişen $2 \times 2$ matristir. Çalışmada, Salvador ve Aragó (2014)'nun ortalama denklemi (birinci moment) kullanılmıştır. Sonrasında ise ortalama denkleminden elde edilen hatalar kullanılarak ikinci moment bağlamında diyagonal VECH ve diyagonal BEKK modelleri tahmin edilmiştir.

Bollerslev vd. (1988) tarafından önerilen VECH GARCH $(p, q)$ modeli denklem 10.'da yer almaktadır.
Burada " $C$ ", $N=2$ olmak üzere $\frac{1}{2} N(N+1) x 1$ 'den $3 x 1$ vektör, " $A_{i}$ " ve " $B_{\mathrm{j}}$ " ise $\frac{1}{2} N(N+1) x \frac{1}{2} N(N+1)$ 'den $3 \times 3$ parametre matrisleridir. Ancak bu modelle toplamda 21 parametre tahmini gerektiğinden, Bollerslev vd. (1988) tahmin edilecek parametre sayısını

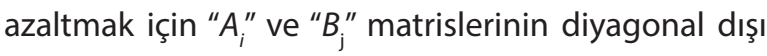
bileşenlerinin sıfır yapıldığı diyagonal VECH modelini önermişlerdir. Bu model bağlamında, " $h_{i j, t}$ ", sırasıyla $h_{s s, t}, h_{f f, t}$ ve $h_{s f, t}$ olarak ifade edilmek üzere, " $h_{s s, t}$ ", $e_{s, t}$ 'nin koşullu varyansı, " $h_{f f, t}$ ", $e_{f, t}$ 'nin koşullu varyansı ve $h_{s f, t}$ getiri serilerinin koşullu kovaryansı olmak üzere denklem 11., 12. ve 13. tahmin edilebilir.

$$
\begin{aligned}
& \operatorname{vech}\left(H_{t}\right)=C+\sum_{i=1}^{q} A_{i} \operatorname{vech}\left(e_{t-i} e_{t-i}^{\prime}\right)+\sum_{j=1}^{p} B_{j} \operatorname{vech}\left(H_{t-j}\right) \\
& h_{s s, t}=c_{s s}+\alpha_{s s} e_{s, t-1}^{2}+\beta_{s s} h_{s s, t-1}
\end{aligned}
$$

${ }^{4}$ Bu kapsamda, Floros ve Vougas (2004); Yang ve Allen (2004); Kavussanos ve Visvikis (2008); Sultan ve Hasan (2008); Lee, Wang ve Chen (2009); Degiannakis ve Floros (2010); Salvador ve Aragó (2014)'nun çalışmaları incelenebilir. 


$$
\begin{aligned}
& h_{f f, t}=c_{f f}+\alpha_{f f} e_{f, t-1}^{2}+\beta_{f f} h_{f f, t-1} \\
& h_{s f, t}=c_{s f}+\alpha_{s f} e_{s, t-1} e_{f, t-1}+\beta_{s f} h_{s f, t-1}
\end{aligned}
$$

Engle ve Kroner (1995) tarafından önerilen GARCH(1,1) BEKK modeli, denklem 14.'te yer almaktadır.

$$
H_{t}=C^{\prime} C+A^{\prime} e_{t-1} e_{t-1}^{\prime} A+B^{\prime} H_{t-1} B
$$

Burada, $C=\left(\begin{array}{c}c_{11} c_{12} \\ 0\end{array} c_{22}\right) A=\left(\begin{array}{l}a_{11} a_{12} \\ a_{21} a_{22}\end{array}\right) B=\left(\begin{array}{l}b_{11} b_{12} \\ b_{21} b_{22}\end{array}\right)$ olmak üzere, $C$ sabit terimlerin tahmin edilecek bir üçgensel matrisi ve $A$ ile $B$ katsayıların tahmin edilecek $2 \times 2$ kare matrisidir (Salvador ve Aragó, 2014). Tahmin edilecek parametre sayısını azaltmak için, $D$ diyagonal bir

$$
H_{t}=C^{\prime} C+A^{\prime} e_{t-1} e_{t-1}^{\prime} A+D E\left[A^{\prime} e_{t-1} e_{t-1}^{\prime} A\right] D
$$

matris ve $B=A D$ olmak üzere, $i=1,2$ için durağanlık $a_{i i}^{2}+b_{i i}^{2}<0$ ile sağlanmak üzere, diyagonal BEKK modeli denklem 15. ile tahmin edilebilir (Chang vd., 2011).

Diyagonal VECH ve diyagonal BEKK modellerinin tahmin edilmesinden sonra dinamik korunma oranı denklem 16. ile hesaplanabilir ki burada $h_{s f, t}$ ve $h_{(f, t)}^{2}$ sırasıyla, yukarıdaki diyagonal VECH ve BEKK modelinde tahmin edilen koşullu kovaryans ve koşullu varyans değerleridir.

$$
H R=\frac{\hat{h}_{s f, t}}{\hat{h}_{f, t}^{2}}
$$

Çalışmada, farklı modeller çerçevesinde çeşitli korunma zamanlarındaki korunma performanslarının da hesaplanması gerekmektedir. Çalışmada korunma performansı, $[\operatorname{VAR}(U)-\operatorname{VAR}(H)] / \operatorname{VAR}(U)$ formülü ile hesaplanmıştır. Burada, "VAR(U)" korunulmayan portföyün getiri varyansı, " $V A R(H)$ " ise korunulan portföyün getiri varyansıdır. Korunma performansının hesaplanmasındaki amaç, elde edilen korunma oranı ile oluşturulacak korunulan portföy sayesinde, korunulmayan portföyün getiri varyansının yüzde kaç azaltılacağının hesaplanmasıdır. Korunulmayan porftöy spot piyasanın kendisidir ve dolayısıyla, $\operatorname{VAR}(U)$ 'nun hesaplanması, günlük veya 1, 2, 3 veya 4 haftalık spot getirilerin varyansının hesaplanması ile elde edilebilir. Korunulan portföyün getirisi ise $r_{H}=\left(s_{t}-s_{t-1}\right)-h\left(f_{t}-f_{t-1}\right)$ formülü ile hesaplanabilir. Burada, " $r_{H}$ " korunulan portföyün getirisi olmak üzere, " $S_{t}$ " logaritmik spot fiyat, " $f_{t}$ "logaritmik futures fiyat ve" $h$ " korunma oranıdır. ise $\operatorname{VAR}(H)$ 'nin varyansıdır.

\subsection{Araştırma Bulguları}

Çizelge 1.'de BIST 30 endeksi spot ve futures getiri serilerinin günlük, 1, 2, 3 ve 4 haftalık korunma zamanları için tanımlayıcı istatistikleri yer almaktadır. 4. hafta hariç olmak üzere diğer tüm korunma zamanlarındaki getiri serilerinde aşırı çarpıklık mevcutken, ayrıca getiri serilerinde aşırı basıklık söz konusudur. Jarque Bera test sonuçları incelendiğinde ise 4 haftalık getiri serileri ve 3 haftalık futures getiri serisi hariç olmak üzere diğer seriler için getirilerin normal dağıldığına dair sıfır hipotezi reddedilmektedir.

Korunma zamanlarına ait logaritmik spot ve futures fiyatlar ile bunların birinci farklarına ait ADF birim kök testi ${ }^{5}$ sonuçlarına göre ise tüm korunma zamanları için logaritmik spot ve futures fiyat serilerinin düzeyde birim kök içerdiklerine dair sıfır hipotezi kabul edilmektedir. Tüm logaritmik spot ve futures fiyat serilerinin birinci farkları için ise sıfır hipotezi reddedilmektedir. Dolayısıyla, spot ve futures fiyat serilerinin birinci farkları durağandır, spot ve futures fiyat serileri I(1)'dir ${ }^{6}$. 
Çizelge 1: Periyotlar Bazında Spot ve Futures Getirilerin Tanımlayıcı İstatistikleri

\begin{tabular}{|l|l|l|l|l|l|}
\hline Periyot & Getiri & Ortalama & Çarpıklık & Basıklık & Jarque-Bera \\
\hline \multirow{2}{*}{ Günlük } & & 0,000163 & $-0,127604$ & 6.176726 & $955.1551^{*}$ \\
\hline \multirow{2}{*}{ Haftalık } & 0,000168 & $-0,167077$ & 5,859682 & $779,5526^{*}$ \\
\hline \multirow{2}{*}{ 2 Haftalık } & 0,000778 & $-0,203886$ & 4,604903 & $53,0118^{*}$ \\
\hline \multirow{3}{*}{ 3 Haftalık } & 0,000789 & $-0,251305$ & 4,440377 & $44,9945^{*}$ \\
\hline \multirow{2}{*}{ 4 Haftalık } & 0,001496 & $-0,792472$ & 5,398983 & $80,2603^{*}$ \\
\cline { 2 - 5 } & & 0,001502 & $-0,806235$ & 5,867879 & $105,0907^{*}$ \\
\cline { 2 - 5 } & & 0,002313 & $-0,516838$ & 3,741159 & $10,5157^{*}$ \\
\hline
\end{tabular}

* \%5 düzeyinde anlamlııı̆ı belirtmektedir.

Çizelge 2.'de çeşitli korunma zamanları çerçevesinde çalışmada kullanılan 6 model ile elde edilen korunma oranları yer almaktadır. Buna göre, günlük korunmada, en iyi korunma oranı ECM-GARCH modeli ile elde edilmiştir. Elde edilen bu bulgu, Degiannakis ve Floros (2010)'un Güney Afrika endeks futures piyasası için günlük korunma bağlamında en iyi korunma oranının ECM-GARCH modeliyle elde edildiği ve ECM-GARCH modelinin çok değişkenli GARCH modellerinden daha iyi bir korunma oranını sağladığına dair bulgular ile örtüşmektedir.

1,3 ve 4 haftalık korunma zamanları çerçevesinde en iyi korunma oranları ise diyagonal BEKK-GARCH modeli ile elde edilirken, 2 haftalık korunma zamanı için en iyi korunma oranı ise diyagonal $\mathrm{VECH}$ GARCH modeli ile elde edilmiştir. Bu bağlamda daha uzun zamanlı korunma için, çok değişkenli GARCH modellerinin diğer modellerden daha iyi bir korunma oranını netice verdiği anlaşılmaktadır. Çok değişkenli GARCH modellerinin daha iyi korunma oranlarını netice verdiğine dair bu bulgu ise, Yang ve Allen (2004)'ın Avustralya piyasası için elde ettikleri, Lee vd. (2009)'nin ABD, Japonya, Tayvan, Hong Kong, Singapur ve Kore piyasaları için elde ettikleri, Floros ve Vougas (2004)'ın Yunanistan piyasası elde ettikleri ve Sultan ve Hasan (2008)'ın Hollanda ve Birleşik Krallık piyasaları için elde ettikleri bulgular ile örtüşmektedir. Öte taraftan, farklı korunma zamanlarındaki korunma oranları incelendiğinde, korunma oranlarının korunma zamanıyla birlikte artma eğiliminde olduğu görülmektedir ki bu bulgu, Lindahl (1992), Holmes (1996), In ve Kim (2006), Kavussanos ve Visvikis (2008) ile Lee vd. (2009)'nin bulguları örtüşmektedir.

Çizelge 2: Çeşitli Korunma Zamanları Çerçevesinde Farklı Modeller ile Elde Edilen Korunma Oranları

\begin{tabular}{|l|c|c|c|c|c|c|}
\hline & OLS & ECM & GARCH & ECM-GARCH & $\begin{array}{c}\text { Diag-VE- } \\
\text { CH-GARCH }\end{array}$ & $\begin{array}{c}\text { Diag-BEKK- } \\
\text { GARCH }\end{array}$ \\
\hline Günlük & 0,937926 & 0,942401 & 0,953439 & 0,957785 & 0,954618 & 0,954805 \\
\hline 1 Haftalık & 0,983792 & 0,975790 & 0,975532 & 0,972611 & 0,986451 & 0,987756 \\
\hline 2 Haftalık & 0,960765 & 0,966425 & 0,971172 & 0,972318 & 0,984362 & 0,984062 \\
\hline 3 Haftalık & 0,987050 & 0,982340 & 0,985623 & 0,976916 & 0,990159 & 0,992633 \\
\hline 4 Haftalık & 0,972884 & 0,976094 & 0,978152 & 0,981889 & 0,984115 & 0,984735 \\
\hline
\end{tabular}

Çok değişkenli GARCH modelleri ile elde edilen korunma oranları zamana bağlı olarak değişmektedir. Çizelge 2.'de yer alan diag VECH-GARCH ve diag
BEKK-GARCH korunma oranları ortalama korunma oranları olarak çizelgede yer almıştır. Çizelge 3.'te çok değişkenli GARCH modelleri ile elde edilen zamana 
bağlı korunma oranlarının, çeşitli korunma zamanları çerçevesindeki tanımlayıc istatistikleri yer almaktadır. Buna göre, örneğin, 1 haftalık, 3 haftalık ve 4 haftalık korunma zamanları için en iyi korunma oranını veren diag BEKK-GARCH modeli ile, 1 haftalık korunma zamanı için ortalama korunma oranının 0,9843, maksimum korunma oranının 1,1431 ve minumum korunma oranının ise 0,9148 olduğu anlaşılmaktadır.
Şekil 1.'de diag BEKK-GARCH modelinin 1 haftalık korunma zamanı için zamana bağlı değişen korunma oranı grafiği yer almaktadır. Buna göre, endeks futures işlemlerin ilk başlangıç dönemleri (2005 sonu-2006 başı) ile 2007-2008 küresel finansal krizin etkilerinden kaynaklı olarak 2008 ve 2009 yıllarında, korunma oranlarının diğer dönemlere göre çok daha dalgalı olduğu dikkati çekmektedir.

Çizelge 3: Çok Değişkenli GARCH Korunma Oranlarının Çeşitli Korunma Zamanları için Tanımlayıcı İstatistikleri

\begin{tabular}{|l|l|l|l|l|l|l|}
\hline & & Maksimum & Minumum & Ortalama & Varyans & Medyan \\
\hline \multirow{2}{*}{ Günlük } & DiagVECH & 1,154661 & 0,837696 & 0,954618 & 0,001808 & 0,955206 \\
\cline { 2 - 7 } & DiagBEKK & 1,156250 & 0,844512 & 0,954805 & 0,001922 & 0,953056 \\
\hline \multirow{2}{*}{ Haftalık } & DiagVECH & 1,088571 & 0,938119 & 0,986451 & 0,000446 & 0,983740 \\
\cline { 2 - 7 } & DiagBEKK & 1,143187 & 0,914826 & 0,987756 & 0,000943 & 0,985355 \\
\hline \multirow{2}{*}{ Haftalık } & DiagVECH & 1,134721 & 0,923538 & 0,984362 & 0,000490 & 0,981483 \\
\cline { 2 - 7 } & DiagBEKK & 1,107016 & 0,925834 & 0,984062 & 0,000401 & 0,981807 \\
\hline \multirow{2}{*}{ Haftalık } & DiagVECH & 1,075968 & 0,965693 & 0,990159 & 0,000338 & 0,985092 \\
\cline { 2 - 7 } & DiagBEKK & 1,080256 & 0,965018 & 0,992633 & 0,000509 & 0,987313 \\
\hline \multirow{2}{*}{ Haftalık } & DiagVECH & 1,003393 & 0,958271 & 0,984115 & 0,000115 & 0,986246 \\
\cline { 2 - 7 } & DiagBEKK & 1,009083 & 0,953319 & 0,984735 & 0,000159 & 0,986170 \\
\hline
\end{tabular}

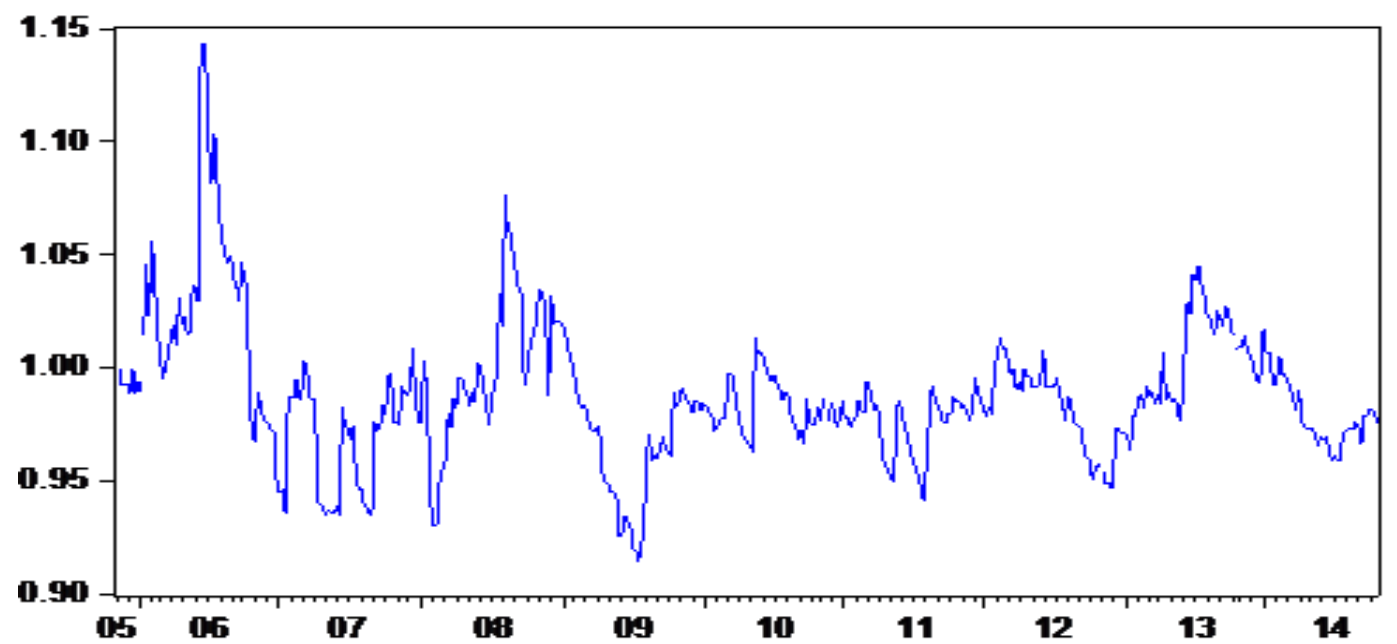

Şekil 1: Diag BEKK-GARCH Modeli Zamana Bağlı Değişen Korunma Oranları (1 Haftalık Korunma Zamanı için)

Korunma oranlarının hesaplanmaları bir yana, bu korunma oranları doğrultusunda korunulacak portföyün performanslarının hesaplanması gerekmektedir. Çizelge 4.'te farklı modeller ile elde edilen korunma oranları üzerinden hesaplanan korunma performansları yer almaktadır. Bu korunma performansları öncelikle, korunulmayan portföyün varyansındaki yüzde azalışlar açısından hesaplanmıştır. Buna göre, OLS modeli ile elde edilen korunma oranlarıyla; günlük, 2 haftalık ve 4 haftalık korunma zamanları için en iyi korunma performansları sağlanmaktadır. 1 haftalık korunma 
zamanı için diag BEKK-GARCH modeli en iyi korunma performansını sağlarken, 3 haftalık korunma zamanı için ise diag VECH-GARCH modeli en iyi performansı sağlamaktadır.

Aynı korunma zamanları için farklı modellerin performanslarıincelendiğinde, modellerin birbirlerine yakın performanslar sağladıkları görülmektedir. Bu durum tüm modeller için korunulan portföyün getiri varyanslarının birbirlerine yakın değerler olması nedeniyledir. Farklı korunma zamanları için korunma performansları incelendiğinde ise korunma zamanı arttıkça korunma performanslarının da arttığı görülmektedir. Dolayısıyla daha uzun zamanlı korunma ile daha iyi bir korunmanın elde edilebileceğine erişilmektedir ki bu bulgu Holmes (1996) ile In ve Kim (2006)'in elde ettiği bulgular ile aynı doğrultudadır.

Diğer taraftan, çizelge 4. bağlamındaki korunma performansları için sadece korunulmayan portföyün varyansındaki yüzde azalışın dikkate alınıyor olması ve korunulan portföyün getirisinin ise dikkate alınmaması bir eksikliktir. Bu bağlamda, Yang ve Allen (2004) takip edilerek, korunulan portföyün getirisi de dikkate alındığında risk-getiri perspektifinde daha ideal bir değerlendirme yapılabilecektir. Çizelge 4.'te yer alan çeşitli korunma zamanları incelendiğinde, günlük ve haftalık korunma için ECM-GARCH, 2 ve 4 haftalık korunma için OLS, üç haftalık korunma için diag-BEKK-GARCH modellerinin en büyük korunulan portföy getirilerini sağladığına erişilmektedir. Varyanstaki yüzde azalış ta getiri ile birlikte dikkate alındığında ise sadece 2 ve 4 haftalık korunma zamanları için hem risk hem getiri bağlamında en iyi modelin OLS olduğuna erişilmektedir. OLS modelinin basit olmakla beraber beş farklı korunma zamanı içerisinden ikisinde risk-getiri bağlamında en iyi korunma performansını sağladığına dair bu bulgu ise, Holmes (1996)'un OLS'in daha gelişmiş modellerden daha iyi performans sergilediğine dair elde ettiği bulgu ile kesişmektedir.

Öte yandan, diğer korunma zamanlarında (günlük, haftalık ve 3 haftalık) ise risk ve getiri açısından en iyi model farklılaşmaktadır. Elde edilen bu bulgu ise, Yang ve Allen (2004)'ın Avustralya piyasası için çeşitli modellerin performanslarına dair elde ettikleri, risk ve getiri bağlamında modellerin performanslarının farklılaştığına dair bulgu ile örtüşmektedir. Yine bu bulgu, Kavussanos ve Visvikis (2008)'in Yunanistan endeks futures piyasalarına dair sabit ve zamana bağlı değişen korunma oranlarının örneklem içi ve örneklem dışı performanslarının farklılaştığına dair bulgu ile kesişmektedir.

Elde edilen tüm bu bulgular doğrultusunda, farklı modellerin çeşitli korunma zamanlarındaki performansları açısından bir "en iyi model" belirsizliğine ulaşılmaktadır. $\mathrm{Bu}$ bulgu ise, Lee vd. (2009)'nin ABD, Japonya, Tayvan, Hong Kong, Singapur ve Kore piyasaları için elde ettikleri, endeks futures piyasaların korunmada etkin oldukları, ancak OHR için bir en iyi model belirsizliğine dair sonuçları ile benzerlik arz etmektedir. 
Çizelge 4: Farklı Modeller için Korunma Performansları

\begin{tabular}{|c|c|c|c|c|c|}
\hline & & $\begin{array}{c}\text { KORUNULAN } \\
\text { POZISYONUN } \\
\text { GETIRISi }\end{array}$ & $\begin{array}{c}\text { KORUNULAN } \\
\text { POZISYONUN } \\
\text { VARYANSI }\end{array}$ & $\begin{array}{c}\text { KORUNULMAYAN } \\
\text { POZISYONUN } \\
\text { VARYANSI }\end{array}$ & $\begin{array}{c}\text { VARYANSTAKI \% } \\
\text { AZALIŞ }\end{array}$ \\
\hline \multirow{6}{*}{ עב } & OLS & $2.44 \mathrm{e}-06$ & 0,00001824 & 0,00006952 & $73,762^{*}$ \\
\hline & ECM & $2.46 \mathrm{e}-06$ & 0,00001827 & 0,00006952 & 73,719 \\
\hline & GARCH & $2.51 e-06$ & 0,00001837 & 0,00006952 & 73,575 \\
\hline & ECM-GARCH & $2.53 \mathrm{e}-06^{*}$ & 0,00001842 & 0,00006952 & 73,504 \\
\hline & Diag-VECH-GARCH & $2.52 \mathrm{e}-06$ & 0,00001838 & 0,00006952 & 73,561 \\
\hline & Diag-BEKK-GARCH & $2.52 \mathrm{e}-06$ & 0,00001839 & 0,00006952 & 73,547 \\
\hline \multirow{6}{*}{ 兰 } & OLS & $8.16 \mathrm{e}-06$ & 0,00003877 & 0,00033320 & 88,36 \\
\hline & ECM & $8.28 \mathrm{e}-06$ & 0,00003898 & 0,00033320 & 88,30 \\
\hline & GARCH & $8.28 \mathrm{e}-06$ & 0,00003898 & 0,00033320 & 88,30 \\
\hline & ECM-GARCH & $8.32 \mathrm{e}-06^{*}$ & 0,00003908 & 0,00033320 & 88,27 \\
\hline & Diag-VECH-GARCH & $8.12 \mathrm{e}-06$ & 0,00003872 & 0,00033320 & 88,37 \\
\hline & Diag-BEKK-GARCH & $8.10 \mathrm{e}-06$ & 0,00003870 & 0,00033320 & $88,38^{*}$ \\
\hline \multirow{6}{*}{ 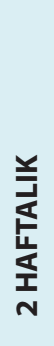 } & OLS & $-7.89 e-06^{*}$ & 0,00003736 & 0,00061697 & $93,94^{*}$ \\
\hline & ECM & $-7.99 e-06$ & 0,00003755 & 0,00061697 & 93,91 \\
\hline & GARCH & $-8.07 e-06$ & 0,00003777 & 0,00061697 & 93,87 \\
\hline & ECM-GARCH & $-8.09 e-06$ & 0,00003783 & 0,00061697 & 93,86 \\
\hline & Diag-VECH-GARCH & $-8.30 e-06$ & 0,00003867 & 0,00061697 & 93,73 \\
\hline & Diag-BEKK-GARCH & $-8.29 e-06$ & 0,00003865 & 0,00061697 & 93,73 \\
\hline \multirow{6}{*}{ 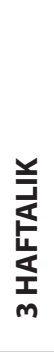 } & OLS & $1.17 e-05$ & 0,00005285 & 0,00094064 & 94,38 \\
\hline & ECM & $1.11 \mathrm{e}-05$ & 0,00005289 & 0,00094064 & 94,37 \\
\hline & GARCH & $1.15 \mathrm{e}-05$ & 0,00005285 & 0,00094064 & 94,38 \\
\hline & ECM-GARCH & $1.05 e-05$ & 0,00005304 & 0,00094064 & 94,36 \\
\hline & Diag-VECH-GARCH & $1.20 \mathrm{e}-05$ & 0,00005286 & 0,00094064 & $94,38^{*}$ \\
\hline & Diag-BEKK-GARCH & $1.23 e-05^{*}$ & 0,00005289 & 0,00094064 & 94,37 \\
\hline \multirow{6}{*}{ 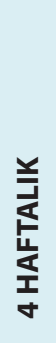 } & OLS & $4.71 \mathrm{e}-05^{*}$ & 0,00004234 & 0,00122087 & $96,53^{*}$ \\
\hline & ECM & $4.70 \mathrm{e}-05$ & 0,00004253 & 0,00122087 & 96,51 \\
\hline & GARCH & $4.70 \mathrm{e}-05$ & 0,00004270 & 0,00122087 & 96,50 \\
\hline & ECM-GARCH & $4,69 e-05$ & 0,00004304 & 0,00122087 & 96,47 \\
\hline & Diag-VECH-GARCH & $4,68 e-05$ & 0,00004327 & 0,00122087 & 96,45 \\
\hline & Diag-BEKK-GARCH & $4,68 e-05$ & 0,00004334 & 0,00122087 & 96,45 \\
\hline
\end{tabular}

Çizelge 5.te ise günlük korunma bağlamında vadeye kalan zaman ile OLS korunma oranları arasındaki ilişki yer almaktadır. Buna göre, vadeye 9 hafta kaladan 6 hafta kalaya değin korunma oranları haftalar bazında giderek artmakta, ayrıca vadeye 3 hafta kaladan vade haftasına kadar da korunma oranları yine haftalar itibariyle artmaktadır. Aradaki haftalarda ise net bir değişim yoktur. Bu bulgular 
itibariyle, özellikle futures kontrat "en yakın vadeli" kontrat statüsünü elde etmesinden itibaren kalan vadesinin yaklaşık yarısına kadar, vadeye kalan haftalar azaldıkça korunma oranları artmaktadır. Benzer şekilde, futures kontratın "kapanmadan" önceki son üç haftasında da vade yaklaştıkça korunma oranları artmaktadır. Dolayısıyla, kontratın vadeye kalan zamanı azaldıkça korunma oranının artı̆ğına dair kısmi bir kanıta erişilmektedir bu Holmes (1996)'un elde ettiği kısmi kanıt ile aynı doğrultuda olup, Lindahl (1992)'ın bulguları ile de kesişmektedir.

Çizelge 5: Vadeye Kalan Zamanın Korunma Oranları Üzerine Etkisi

\begin{tabular}{|c|c|}
\hline Vadeye Kalan Hafta & OLS Korunma Oranları \\
\hline 9 Hafta & 0,912238 \\
\hline 8 Hafta & 0,922618 \\
\hline 7 Hafta & 0,947616 \\
\hline 6 Hafta & 0,966706 \\
\hline 5 Hafta & 0,894238 \\
\hline 4 Hafta & 0,963320 \\
\hline 3 Hafta & 0,928706 \\
\hline 2 Hafta & 0,938311 \\
\hline 1 Hafta & 0,954791 \\
\hline
\end{tabular}

\section{SONUÇ}

Çalışmada, Türkiye futures piyasasında en büyük ağırlığa sahip BIST 30 endeks futures kontratları ile korunma araştırılmış, bu bağlamda 1 Kasım 2005 ve 30 Ekim 2014 arası günlük veriler kullanılarak günlük, 1, 2, 3 ve 4 haftalık beş farklı korunma zamanı perspektifinde optimum korunma oranları ve korunma performansları hesaplanmıştır. Optimum korunma oranlarının hesaplanmasında OLS, ECM, GARCH, ECM-GARCH, diag ECM-GARCH ve diag BEKK-GARCH modelleri olmak üzere altı farklı model kullanılarak klasik ve gelişmiş modellerin yer aldığı karşılaştırmalı bir analiz gerçekleştirilmiştir. Çalışmada ayrıca günlük korunma bağlamında, endeks futures kontratın vadeye kalan zamanının azalması ile OHR arasındaki ilişki de incelenmiştir.

Farklı modellerin korunma oranlarına dair elde edilen bulgular bir arada değerlendirildiğinde, günlük korunmada en yüksek korunma oranı ECM-GARCH ve diğer korunma zamanları için en iyi korunma oranları ise çok değişkenli GARCH modelleri ile elde edilmiş ve gelişmiş modellerin klasik modellere göre daha iyi korunma oranlarını netice verdiğine erişilmiştir. Ayrica, BIST 30 endeks futures kontratlarla korunma zamanı arrtıkça, korunma oranları da artma eğilimi sergilemektedir.

Korunma performansları açısından ise sadece varyanstaki azalış dikkate alındığında; günlük korunma ile 2 ve 4 haftalık korunma zamanları için klasik OLS modeli en iyi performansları sağlarken, 1 haftalık korunma zamanı için diag BEKK-GARCH modeli ve 3 haftalık korunma zamanı için ise diag VECH-GARCH modeli en iyi performansı sağlamaktadırlar. Hem getiri hem de varyanstaki azalış bağlamında performans açısından ise 2 ve 4 haftalık korunma zamanları için klasik OLS modeli en iyi performansları sağlarken, diğer korunma zamanları için risk ve getiri açısından en iyi model farklılaşmaktadır. Bu bağlamda, modellerin korunma performansları birbirine yakın olup, herhangi bir modelin tek başına tüm korunma zamanları için en iyi performansı sağladığına erişilememiştir. Dolayısıyla, modellerin farklı korunma zamanlarındaki performansları açısından bir en iyi model belirsizliği durumu söz konusudur. Korunma zamanları ve korunma performansları ilişkisi incelendiğinde ise korunma zamanları arttıkça varyanstaki azalış bağlamında korunma performansları da giderek artmakta ve 1'e yaklaşmaktadır. Futures kontratların vadeye kalan zamanı ile korunma oranları arasındaki ilişki incelendiğinde ise vadeye kalan zaman azaldıkça OHR'nin arttığına dair kısmi bir kanıta erişilmiş̧tir.

Elde edilen bu bulgular bir arada değerlendirildiğinde ise, BIST 30 endeks futures kontratların, futures kontratların en önemli amaçlarından biri olan korunmaya önemli bir şekilde hizmet ettiği sonucuna varılmıştır. Bu bulgu ve sonuçlar ise başta yatırımcılar olmak üzere, piyasa pratisyenleri ve araştırmacılar için önem arz etmektedir. Yatırımcılar hangi korunma zamanını tercih ettiklerine göre, risk-getiri dengelemesi bağlamında ilgili korunma zamanı için uygun olan modelin korunma oranını daha iyi performans için baz alabilirler. Yatırımcılar ayrıca, bu korunma oranlarını kontratın vadeye kalan zamanı doğrultusunda revize etme yoluna da gidebilirler.

İleriki çalışmalara yönelik olarak, Türkiye piyasalarına dair küçük dalga analizi ve risklilik endeksleri kullanılarak korunma performanslarının elde edilmesi, daha detaylı tahliller adına fayda sağlayacaktır. 


\section{KAYNAKÇA}

Bollerslev, T. (1986) "Generalized Autoregressive Conditional Heteroskedasticity" Journal of Econometrics, 31(3): 307-327.

Bollerslev, T., Engle, R. F. ve Wooldridge, J. M. (1988) "A Capital Asset Pricing Model with Time-Varying Covariances" Journal of Political Economy, 96(1): 116131.

Chang, C.-L., McAleer, M. ve Tansuchat, R. (2011)“Crude Oil Hedging Strategies Using Dynamic Multivariate GARCH" Energy Economics, 33(5): 912-923.

Çelik, İ. (2014) «Vadeli İşlem Piyasasında Optimal Hedge Rasyosunun Statik ve Dinamik Teknikler Yardımıyla Hesaplanması» Uluslararası Alanya Iş̧letme Fakültesi Dergisi, 6(3): 1-13.

Degiannakis, S. ve Floros, C. (2010) "Hedge Ratios in South African Stock Index Futures" Journal of Emerging Market Finance, 9(3): 285-304.

Ederington, L. H. (1979) "The Hedging Performance of the New Futures Markets" The Journal of Finance, 34(1): 157-170.

Engle, R. F. (1982) "Autoregressive Conditional Heteroscedasticity with Estimates of the Variance of United Kingdom Inflation" Econometrica, 50(4): 9871007.

Engle, R. F. ve Kroner, K. F. (1995) "Multivariate Simultaneous Generalized ARCH" Econometric Theory, 11(1): 122-150.

Engle, R. ve Granger, C. (1987) "Cointegration and Error Correction: Representation, Estimation, and Testing" Econometrica, 55(2): 251-276.

Figlewski, S. (1985) "Hedging with Stock Index Futures: Theory and Application in a New Market" The Journal of Futures Markets, 5(2): 183-199.

Floros, C. ve Vougas, D. V. (2004) "Hedge Ratios in Greek Stock Index Futures Market" Applied Financial Economics, 14(15): 1125-1136.

Hatemi-J, A. ve Roca, E. (2006) "Calculating the Optimal Hedge Ratio: Constant, Time Varying and the Kalman Filter Approach" Applied Economics Letters, 13(5): 293-299.

Holmes, P. (1995) "Ex Ante Hedge Ratios and the Hedging Effectiveness of the FTSE-100 Stock Index Futures Contract" Applied Economics Letters, 2(3): 5659.

Holmes, P. (1996) "Stock Index Futures Hedging: Hedge Ratio Estimation, Duration Effects, Expiration
Effects and Hedge Ratio Stability" Joumat of Business Finance \& Accounting, 23(1): 63-77.

Hsu, Y.-C. ve Chen, A.-P. (2014) "A Clustering Time Series Model for the Optimal Hedge Ratio Decision Making" Neurocomputing, 138: 358-370.

In, F. ve Kim, S. (2006) "The Hedge Ratio and the Empirical Relationship between the Stock and Futures Markets: A New Approach Using Wavelet Analysis" The Journal of Business, 79(2): 799-820.

Johnson, L. L. (1960) "The Theory of Hedging and Speculation in Commodity Futures" The Review of Economic Studies, 27(3): 139-151.

Kavussanos, M. G. ve Visvikis, I. D. (2008) "Hedging Effectiveness of the Athens Stock Index Futures Contracts" The European Journal of Finance, 14(3): 243-270.

Lee, C.-F., Wang, K. ve Chen, Y. L. (2009) “Hedging and Optimal Hedge Ratios for International Index Futures Markets" Review of Pacific Basin Financial Markets and Policies, 12(4): 593-610.

Lien, D. ve Shrestha, K. (2005) "Estimating the Optimal Hedge Ratio with Focus Information Criterion" The Journal of Futures Markets, 25(10): 1011-1024.

Lien, D. ve Shrestha, K. (2007) "An Empirical Analysis of the Relationship between Hedge Ratio and Hedging Horizon Using Wavelet Analysis" The Journal of Futures Markets, 27(2): 127-150.

Lien, D., Shrestha, K. ve Wu, J. (2015) "Quantile Estimation of Optimal Hedge Ratio" The Journal of Futures Markets. doi:10.1002/fut.21712

Lindahl, M. (1989) "Measuring Hedging Effectiveness With R2: A Note" The Journal of Futures Markets, 9(5): 469-475.

Lindahl, M. (1992) "Minimum Variance Hedge Ratios For Stock Index Futures: Duration and Expiration Effects" The Journal of Futures Markets, 12(1): 33-53.

Olgun, O. ve Yetkiner, I. H. (2011) "Determination of Optimal Hedging Strategy for Index Futures: Evidence from Turkey" Emerging Markets Finance \& Trade, 47(6): 68-79.

Salvador, E. ve Aragó, V. (2014) "Measuring Hedging Effectiveness of Index Futures Contracts: Do Dynamic Models Outperform Static Models? A RegimeSwitching Approach" The Journal of Futures Markets, 34(4): 374-398. 
Stein, J. L. (1961) "The Simultaneous Determination of Spot and Futures Prices" American Economic Review, 51(5): 1012-1025.

Sultan, J. ve Hasan, M. S. (2008) "The Effectiveness of Dynamic Hedging: Evidence from Selected European Stock Index Futures" The European Journal of Finance, 14(6): 469-488.
Working, H. (1953) "Futures Trading and Hedging" The American Economic Review, 43(3): 314-343.

Yang, W. ve Allen, D. E. (2004) "Multivariate GARCH Hedge Ratios and Hedging Effectiveness in Australian Futures Markets" Accounting and Finance, 45(2): 301321. 